\title{
Worldwide Spatial and Temporal Distribution of Tuberculosis (TB)
}

Solomon Meseret Woldeyohannes ${ }^{1 *}$ and Sisay Yifru Abera ${ }^{2}$

${ }^{1}$ Department of Epidemiology and Biostatistics, Institute of Public Health, University of Gondar, Gondar, Ethiopia

${ }^{2}$ Department of Pediatrics, College of Medicine and Health Sciences, University of Gondar, Gondar, Ethiopia

\begin{abstract}
Background: A detailed analysis of the spatio-temporal correlation of the yearly geo-referenced data indicated that the information obtained through such analysis can contribute to more effective in budget allocation, drug distribution and recruitment of human skilled resources, as well as guiding the design of vaccination programs. Hence, the current literature review was conducted to show the global spatial and temporal distribution of TB and importance of research regarding worldwide spatial and temporal distribution of tuberculosis in TB control programs.

Objective: The purpose of the literature review was to assess the worldwide spatial and temporal distribution of tuberculosis.

Methods: The literature review was done through identification and evaluation of a range of different types of sources including academic and professional journal articles, books, and web-based resources. Search engines were used to search web resources and bibliographic databases following aspects of the process associated with the production of a literature review such as evaluating information sources, searching and locating information resources, developing conceptual framework and mind mapping, and writing the literature review. In addition, references which had themes in common were grouped together. Finally, reflections on the findings of the literature review were made.

Results and Conclusions: There is sufficient evidence about the existence of significant high-rate space and time TB clustering and spatial variability across study regions. Significant clustering of TB was seen in "TB Epidemic" and hyperendemic "hotspots" often characterized by crowding, HIV infection, unemployment, and other social determinants. General development measures which were correlated with TB incidence trends varied geographically. People movement also found to be another risk factor indicating difference in TB occurrence among countries. The information obtained could contribute to more effective budget allocation, drug distribution and recruitment of human skilled resources, as well as guiding the design of vaccination programs.
\end{abstract}

Keywords: TB; MDR-XDR TB; Spatio-temporal distribution; Clustering; GIS

Abbreviations: CAR: Conditional Auto Regressive; DOTS: Directly Observed Treatment Strategy; Drug: Drug Resistance Tuberculosis; GIS: Geographic Information System; MDGs: Millennium Development Goals; MDR-TB : Multidrug - Resistant Tuberculosis; MTB: Mycobacterium Tuberculosis; OR: Odds Ratio; TB: Tuberculosis; WHA: World Health Assembly; WHO: World Health Organization

\section{Background}

Tuberculosis (TB) is an infectious disease caused by the bacillus Mycobacterium tuberculosis [1]. Mycobacterium tuberculosis (MTB) is a pathogenic bacterial species in the genus Mycobacterium and the causative agent of most cases of tuberculosis. Primarily, it is a pathogen of the mammalian respiratory system, MTB infects the lungs and is the causative agent of tuberculosis [2]. It typically affects the lungs (pulmonary TB) but can affect other sites as well (extrapulmonary $\mathrm{TB})$. The duration of tuberculosis from onset to cure or death is approximately 3 years and appears to be similar for smear-positive and smear-negative tuberculosis [3].

Global targets for reducing the burden of disease caused by TB have been set within the context of the Millennium Development Goals (MDGs). One is to halt and reverse the incidence of TB by 2015. The additional targets set by the Stop TB Partnership are to halve TB prevalence and death rates by 2015 [4,5], compared with their levels in 1990, and eliminate TB as public health problem by 2050 [5]. Indicator 23 (prevalence and death rates) and indicator 24 (the proportion of cases detected and cured under a directly observed treatment strategy) (DOTS) are used to measure progress towards this goal [6]. For indicator 24, as part of WHA resolution, in 1991, the World Health Assembly (WHA) highlighted two indicators: 70\% global and in-country new smear positive cases detection rates and successful treatment of $85 \%$ of such cases by the year 2000 [7-9]. Later on, in 1994, WHO introduced the internationally recommended control strategy, DOTS (Directly Observed Treatment Short-Course) [10] and was implemented in 182 countries [11]. Despite these and availability of highly efficacious treatment for decades, tuberculosis (TB) causes approximately 2 million deaths each year [12], and remains a major and devastating global health problem $[1,13,14]$, and greatest public health challenges of our time $[1,13,15]$. Of nine million new tuberculosis cases each year $[5,12,13]$, nearly half a million are multidrug-resistant tuberculosis (MDR-TB).

The dynamics of infectious diseases depends on the spatial distribution of pathogens and hosts, and the probability of an encounter between them. The transmission of infectious pathogens from infected to susceptible hosts declines with increasing distance between individuals. TB, like many infectious diseases, is prone to spatial

*Corresponding author: Solomon Meseret Woldeyohannes, Department of Epidemiology and Biostatistics, Institute of Public Health, University of Gondar, Gondar, Ethiopia, Tel: 251-0941399138; E-mail: messisol@yhoo.com

Received February 10, 2015; Accepted April 16, 2015; Published April 24, 2015

Citation: Woldeyohannes SM, Abera SY (2015) Worldwide Spatial and Temporal Distribution of Tuberculosis (TB). J AIDS Clin Res 6: 452. doi:10.4172/2155 6113.1000452

Copyright: (C) 2015 Woldeyohannes SM, et al. This is an open-access article distributed under the terms of the Creative Commons Attribution License, which permits unrestricted use, distribution, and reproduction in any medium, provided the original author and source are credited. 
aggregation or clustering $[16,17]$. A cross-sectional study indicated that GIS-based screening can effectively penetrate populations with high disease burden and poor healthcare access. Linkage to care remains challenging and will require creative interventions to impact morbidity [18]. And as TB is known to cluster in hyperendemic "hotspots" often characterized by crowding [16,19], HIV infection [20], and other social determinants [21], new approaches, such as mapping and spatial analysis, may be of value in contributing to basic elements of TB control [22].

The benefits obtained from analyzing the spatial and temporal distribution of tuberculosis in revealing and clarifying processes, structures, etc. and ultimately, its merit of supporting spatial decisionmaking, and to serve as a tool for assisting with regional planning and the formulation of government policies. Though a few researches were conducted at global level on the spatial and temporal distribution of TB, systematic review of the global spatial and temporal distribution and its importance in planning and implementing TB control programs is not yet done. Hence, the current literature review was intended to show the importance of research regarding the spatial and temporal distribution of tuberculosis at global level.

\section{Methods}

The literature review begun by naming and describing tuberculosis and then establishing to show the importance of studying the spatio temporal distribution of TB to be investigated and perhaps by others. Next, a topic-by-topic description of relevant research related to global spatio - temporal distribution of TB was conducted. Also, references which had something in common were grouped together. The results of the research were included. Finally, conflicts or disagreements in the literature were pointed out.

\section{Identification and location of information sources}

The literature review was done through identification and evaluation of a range of different types of sources including academic and professional journal articles, books, and web-based resources. The literature search helped in the identification and location of relevant documents and other sources. Search engines were used to search web resources and bibliographic databases. Hence, the subsequent sections briefly explore the following aspects of the process associated with the production of a literature review: evaluating information sources, searching and locating information resources, developing conceptual framework and mind mapping, and writing the literature review.

Evaluating information resources: The first and main source searched for the purpose of this literature review, was academic and professional literature, articles in scholarly and research journals with firmer theoretical basis, with more critical treatment of concepts and models were considered; those articles which were designed to record and distill systematically researched knowledge in the area, and have typically been peer refereed prior to acceptance for publication. In addition, scholarly and research journals that have reviewed articles and provide a review of all of the recent work in the area of tuberculosis epidemiology with special emphasis on spatio - temporal distribution of tuberculosis. Such reviews included a significant bibliography that had an invaluable source of reference to other work in the area of tuberculosis. Finally, Professional and practitioner journal articles which were useful in identifying recent developments or topical themes in context, policy, legal frameworks, and technological advances were also considered. Another source that, actually not widely searched, was consulted in the literature search was books, standard texts, which include bibliographies or lists of references to other useful sources. Finally, web based resources that were easy to locate through simple searches in standard search engines were searched.

Searching and locating information resources: The following tools were utilized to assist in the identification and location of documents such as library catalogues, search engines and on-line databases.

Developing conceptual frameworks and mind mapping: By constructing computer based concept map, key concepts from the collected documents regarding the spatial and temporal distribution of tuberculosis were identified. Hence, the tool was used to identify additional search terms during the literature search, clarify thinking about the structure of the literature review in preparation for writing the review and understand theory, concepts and the relationships between them. The concept map is a diagram of the issue under study, and represents the concepts in that area and the relationships between them. Concepts are represented by labeled boxes, and relationships are represented by lines. Figure 3 shows concept map for the spatial and temporal distribution of tuberculosis literature review.

Writing the literature review: Five steps in the creation of the literature review were followed: scanning documents, making notes, and structuring the literature review, writing the literature review, and building the bibliography.

Evaluating the sources and documents: The following criteria were considered in evaluating the sources and documents review:

- Relevant to the topic;

- The frequency of update

- The publishing organization

- Links or references to other relevant web, electronic, or print sources

- License or payment necessary for access to the resources

- Up-to-date, as signaled by the publication date;

- Published by a reputable publisher in the discipline;

\section{Results on Literature Review}

Globally, many studies have been conducted and documented the spatial and temporal public health importance of tuberculosis. The following summarizes the literature review on the issue.

\section{Spatial and temporal variation}

Many studies have dominated the importance studying the geographic variation of TB clustering. For instance, a spatial analysis of tuberculosis in Greater Banjul, Gambia, showed significant highand low-rate spatial and space-time clusters in two districts [22]. Another spatial epidemiology and spatial ecology study of worldwide drug resistance tuberculosis indicated the presence of marked spatial variability across study regions [23]. In addition, spatio temporal patterns of multidrug-resistant and drug-sensitive tuberculosis in a South American setting indicated spatial aggregation of patients with confirmed MDR in which cases with confirmed MDR disease were found to be more tightly grouped. Subgroup analysis by the study suggested the appearance of resistance that may be driven by increased transmission [24]. Finally, a study concluded the presence of sufficient evidence about the existence of statistically significant tuberculosis clusters in Almora district of Uttaranchal, India, by showing significant high rate spatial and space-time clusters in three areas of the district [25]. 
Citation: Woldeyohannes SM, Abera SY (2015) Worldwide Spatial and Temporal Distribution of Tuberculosis (TB). J AIDS Clin Res 6: 452. doi:10.4172/2155-6113.1000452

Page 3 of 8

\section{Clustering in endemic and hyperendemic areas}

The spatial epidemiology and spatial ecology study of worldwide drug-resistant tuberculosis have also shown the presence of significant clustering of TB in "TB Epidemic" [23]. Similarly, another study in Portugal showed spatiotemporal clustering of tuberculosis incidence hyperendemic "hotspots" often characterized by crowding [16,19], HIV infection [20], and other social determinants [21]. This finding was supported by study in HIV endemic settings which found that populations with clustering of respiratory contacts experience aggregation of TB cases and high numbers of re-infection events [26].
In addition, another study also pointed out high-incidence hotspots could play an important role in propagating TB epidemics [19].

\section{Global burden of tuberculosis}

Data in parentheses are $95 \%$ uncertainty intervals. Adapted from the 2013 GBD study [27] (Tables 1 and 2).

Table 1 shows a summary at the global and regional level of the ARCs for age-standardised rates of incidence, prevalence, and deaths for tuberculosis in individuals who are HIV-negative.

Figure 1 shows the temporal changes of tuberculosis incident case

\begin{tabular}{|c|c|c|c|}
\hline & \multicolumn{3}{|c|}{ Annualised rate of change (\%) } \\
\hline & \multicolumn{3}{|c|}{ 2000-2013 } \\
\hline & Incidence & Prevalence & Mortality \\
\hline Worldwide & $-0.60(-0.73$ to -0.50$)$ & $-1 \cdot 31(-1 \cdot 41$ to $-1 \cdot 20)$ & $-3.72(-4.42$ to -2.99$)$ \\
\hline High-income Asia Pacific & $0.11(-0.06$ to 0.27$)$ & $0.13(-0.18$ to 0.40$)$ & $-5.03(-5.85$ to -3.99$)$ \\
\hline Central Asia & $-0.76(-0.92$ to -0.58$)$ & $-0.68(-0.85$ to -0.50$)$ & $-4.97(-5.83$ to -4.07$)$ \\
\hline East Asia & $-2 \cdot 08(-2 \cdot 36$ to $-1 \cdot 85)$ & $-3 \cdot 16(-3 \cdot 44$ to $-2 \cdot 86)$ & $-7.54(-8.53$ to -6.63$)$ \\
\hline South Asia & $-1 \cdot 06(-1 \cdot 30$ to $-0 \cdot 80)$ & $-2 \cdot 43(-2.65$ to $-2 \cdot 20)$ & $-4.22(-5.64$ to $-2 \cdot 89)$ \\
\hline Southeast Asia & $-0.54(-0.68$ to -0.42$)$ & $0.12(-0.03$ to 0.28$)$ & $-3.61(-4.42$ to $-2 \cdot 82)$ \\
\hline Australasia & $-0.22(-0.41$ to -0.03$)$ & $-0.36(-0.66$ to -0.08$)$ & $-3.63(-4.62$ to -2.62$)$ \\
\hline Caribbean & $-0.20(-0.35$ to -0.05$)$ & $-1 \cdot 15(-1 \cdot 32$ to $-0 \cdot 98)$ & $-3.93(-4.93$ to -2.50$)$ \\
\hline Central Europe & $-1.61(-1.74$ to $-1 \cdot 50)$ & $-0.29(-0.42$ to -0.17$)$ & $-5.95(-6.43$ to -5.27$)$ \\
\hline Eastern Europe & $-0.58(-0.80$ to -0.39$)$ & $-0.75(-0.97$ to -0.53$)$ & $-4.80(-7.62$ to -3.91$)$ \\
\hline Western Europe & $-1 \cdot 18(-1 \cdot 28$ to $-1 \cdot 08)$ & $-0.64(-0.78$ to -0.52$)$ & $-4.88(-5.53$ to $-3 \cdot 78)$ \\
\hline Andean Latin America & $-0.81(-1.04$ to -0.54$)$ & $-0.78(-1.06$ to -0.52$)$ & $-4.86(-5.88$ to $-3 \cdot 78)$ \\
\hline Central Latin America & $-1.69(-1.83$ to -1.55$)$ & $-1.51(-1.67$ to $-1 \cdot 35)$ & $-4 \cdot 21(-4.74$ to -3.03$)$ \\
\hline Southern Latin America & $-2.56(-2.75$ to $-2 \cdot 39)$ & $-1.56(-1 \cdot 78$ to $-1 \cdot 32)$ & $-3.35(-4.03$ to -2.70$)$ \\
\hline Tropical Latin America & $-1 \cdot 27(-1.50$ to $-1 \cdot 08)$ & $-0.68(-1.04$ to -0.36$)$ & $-4.33(-5.36$ to -3.47$)$ \\
\hline North Africa and Middle East & $-1 \cdot 10(-1 \cdot 18$ to $-1 \cdot 03)$ & $-1 \cdot 26(-1 \cdot 35$ to $-1 \cdot 16)$ & $-4.58(-5.34$ to -3.89$)$ \\
\hline High-income North America & $-3.32(-3.55$ to -3.10$)$ & $-2.28(-2.57$ to -1.97$)$ & $-4 \cdot 14(-5 \cdot 14$ to $-1 \cdot 90)$ \\
\hline Oceania & $0.77(0.60$ to 0.98$)$ & $0.14(-0.09$ to 0.37$)$ & $-2.96(-4.58$ to -0.91$)$ \\
\hline Central sub-Saharan Africa & $0.07(-0.12$ to 0.28$)$ & $-0.17(-0.41$ to 0.06$)$ & $-3.41(-4.67$ to -1.99$)$ \\
\hline Eastern sub-Saharan Africa & $-0.34(-0.52$ to -0.16$)$ & $-0.38(-0.57$ to -0.20$)$ & $-3.08(-4.12$ to $-2 \cdot 40)$ \\
\hline Southern sub-Saharan Africa & $0.14(-0.26$ to 0.54$)$ & $-0.09(-0.41$ to 0.28$)$ & $-4.12(-5.91$ to -2.91$)$ \\
\hline Western sub-Saharan Africa & $-0.57(-0.73$ to -0.39$)$ & $-0.69(-0.86$ to -0.49$)$ & $-3.09(-3.84$ to -2.17$)$ \\
\hline
\end{tabular}

Table 1: Age-standardised tuberculosis without HIV incidence, prevalence, and mortality rates and annualized rates of change for both sexes for 21 Global Burden of Disease regions.

\begin{tabular}{|c|c|c|}
\hline & \multicolumn{2}{|c|}{ Annualised rate of change (\%) } \\
\hline & \multicolumn{2}{|c|}{$2000-13$} \\
\hline & Incidence & Deaths \\
\hline Worldwide & $-0.60(-0.73$ to -0.50$)$ & $-372(-442$ to -2.99$)$ \\
\hline Developed countries & $-1 \cdot 18(-1 \cdot 30$ to $-1 \cdot 07)$ & $-4.94(-6.29$ to -4.37$)$ \\
\hline Developing countries & $-0.91(-1.04$ to -0.80$)$ & $-4 \cdot 01(-470$ to -329$)$ \\
\hline High-income Asia Pacific & $0.11(-0.06$ to 0.27$)$ & $-5.03(-5.85$ to -399$)$ \\
\hline Brunei & $-1 \cdot 23(-1 \cdot 74$ to $-0 \cdot 68)$ & $-365(-5.51$ to -1.69$)$ \\
\hline Japan & $-273(-3.02$ to -243$)$ & $-4 \cdot 61(-598$ to $-2 \cdot 71)$ \\
\hline Singapore & $-1.24(-1.54$ to -0.93$)$ & $-5.48(-6.99$ to -382$)$ \\
\hline South Korea & $0.90(0.68$ to 1.10$)$ & $-553(-6 \cdot 78$ to $-4 \cdot 31)$ \\
\hline Central Asia & $-0.76(-0.92$ to -0.58$)$ & $-4.97(-5.83$ to -4.07$)$ \\
\hline East Asia & $-2 \cdot 08(-236$ to $-1 \cdot 85)$ & $-7.54(-8.53$ to -6.63$)$ \\
\hline China & $-2 \cdot 32(-2 \cdot 62$ to $-2 \cdot 07)$ & $-7 \cdot 77(-8 \cdot 79$ to $-6 \cdot 88)$ \\
\hline North Korea & $1.74(1.42$ to 2.07$)$ & $-3 \cdot 11(-5 \cdot 25$ to -0.71$)$ \\
\hline Taiwan (Province of China) & $0.05(-0.23$ to 0.29$)$ & $-6.30(-8.07$ to -4.41$)$ \\
\hline
\end{tabular}

Data in parentheses are 95\% uncertainty intervals.

Table 2: Tuberculosis without HIV incidence and deaths for all ages by sex and annualised rates of change for 21 Global Burden of Disease regions and 188 countries Adapted for the 2013 GBD study [27] 
Citation: Woldeyohannes SM, Abera SY (2015) Worldwide Spatial and Temporal Distribution of Tuberculosis (TB). J AIDS Clin Res 6: 452. doi:10.4172/2155-6113.1000452

Page 4 of 8

numbers, the number of prevalent cases, and the number of deaths from 1990 to 2013. Total tuberculosis numbers are shown as well as numbers for tuberculosis in individuals who are HIV-negative.
Figure 2 shows maps of age-standardised incidence rates and death rates for tuberculosis in individuals who are HIV-negative in 2013.
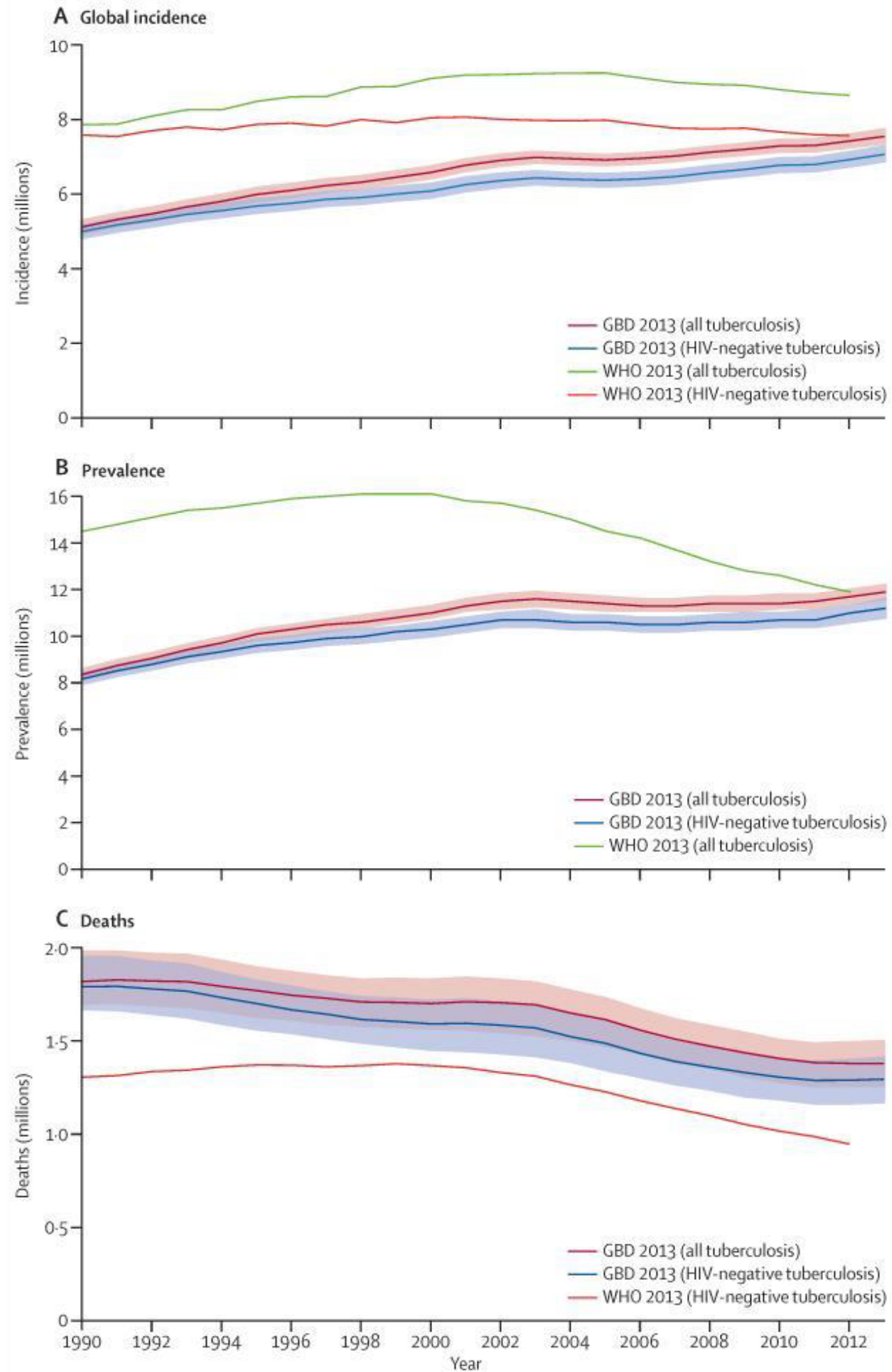

Figure 1: Global tuberculosis incidence (A), prevalence (B), and deaths (C), 1990-2013, for all ages and both sexes combined [27]. Shaded areas show 95\% uncertainty intervals. Adapted from the $2013 \mathrm{GBD}$ study. 
Citation: Woldeyohannes SM, Abera SY (2015) Worldwide Spatial and Temporal Distribution of Tuberculosis (TB). J AIDS Clin Res 6: 452. doi:10.4172/2155-6113.1000452

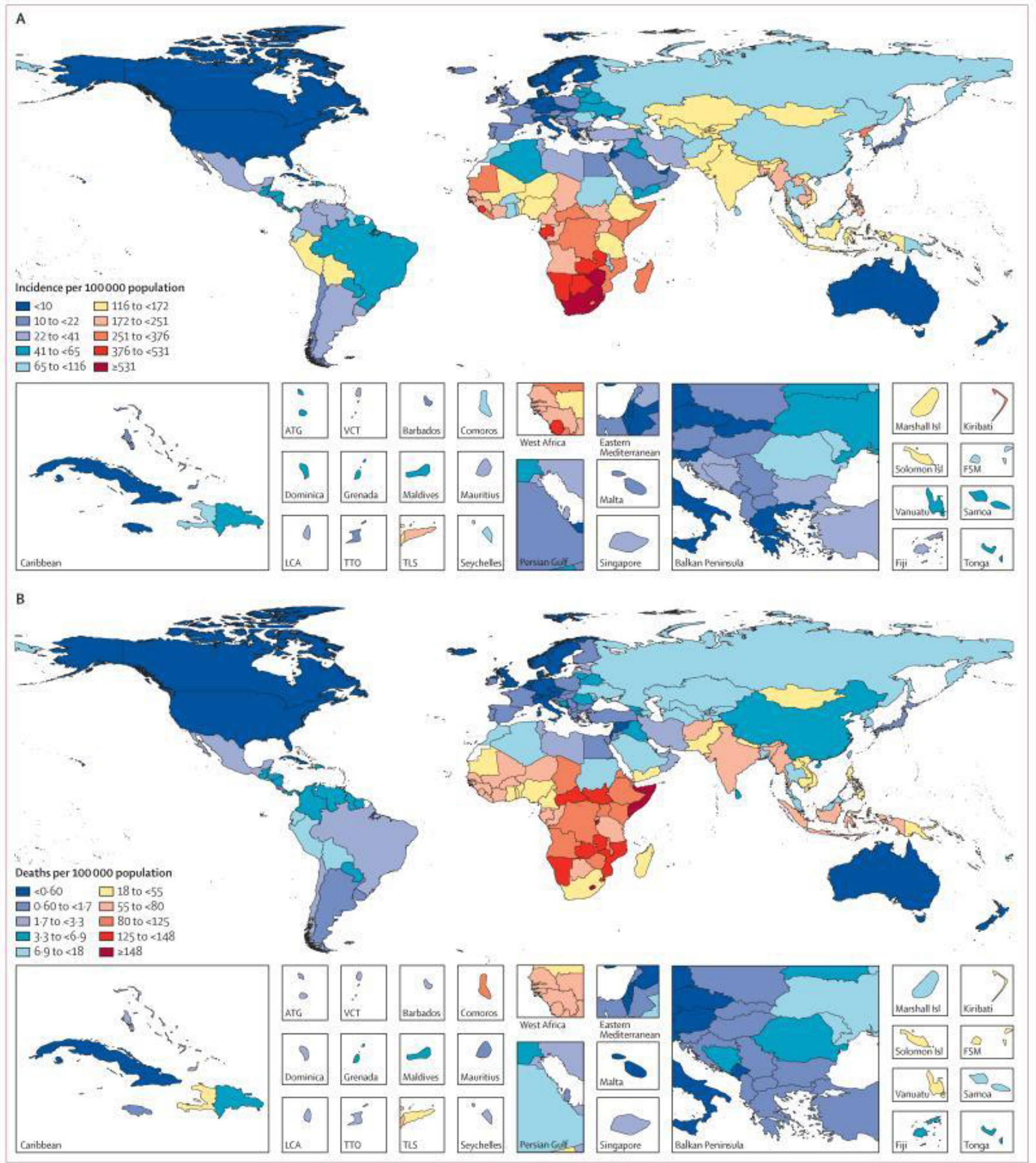

Figure 2: Age-standardised tuberculosis incidence (A) and death rates (B) in HIV-negative individuals in 2013, both sexes [27].

\section{Socio economic determinants}

A spatial analysis tuberculosis transmission patterns in a highincidence area found high tuberculosis notifications with unemployment and its associated poverty having the strongest association with spatial clustering [19]. A study in Antananarivo City indicated that the change in risk of a TB cluster was linked to socio-economic (e.g. household amount of ownership of tap water) and patient care factors (e.g. patients 


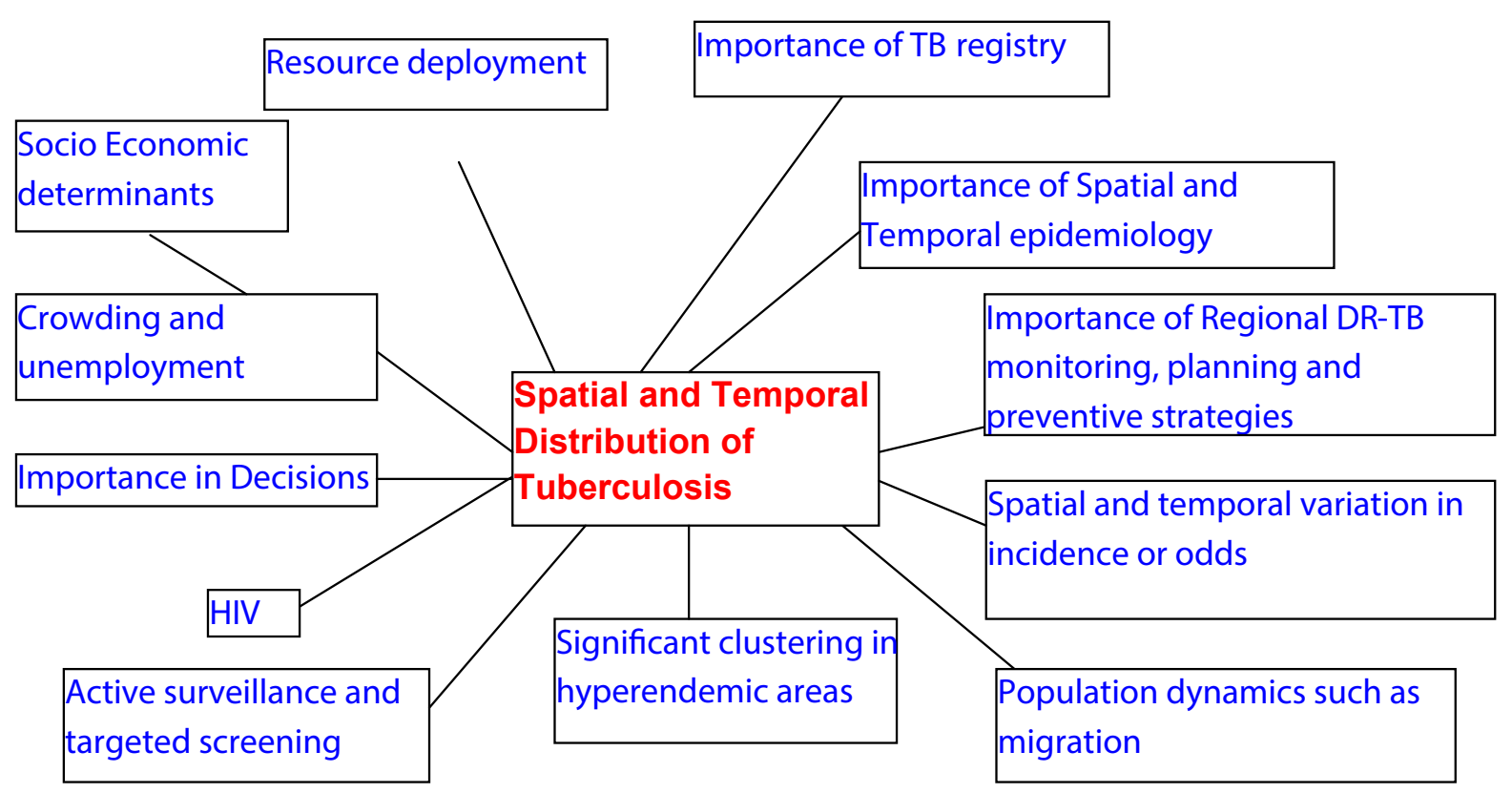

Figure 3: Concept Map relating to Spatial and Temporal Distribution of Tuberculosis.

lost to follow-up) [28]. For instance, Bayesian anlsysi of the patiotemporal patterns of tuberculosis incidence in Ribeireao Preto, Sao Paulo, southeast Brazil, demonstrated that the rate of TB was correlated with the measures of income, education and social vulnerability. The study also observed areas with low vulnerability and high education and income, but with high estimated TB rates [29].

In addition, significant associations of tuberculosis notifications were found with overcrowding $[19,30]$ and the epidemic being most extreme in slum areas [31]. General development measures were also dominant explanatory variables within regions, though correlation with TB incidence trends varied geographically [32]. For instance, mortality due to TB has been declining and incidence was diminishing or stabilizing in all world regions except sub-Saharan Africa and, to some extent, eastern Europe [9].

\section{Population dynamics such as migration as factor}

People movement also found to be another risk factor indicating difference in TB occurrence among countries. For instance, travel to the country of origin was a risk factor for TB among Moroccans, but not among Turkish people living in the Netherlands. The difference in travel-associated odds ratio (OR) between these two immigrant groups is probably related to differences in TB incidence in these countries [33]. Another study in Beijing on the impact of new migrant populations on the spatial distribution of tuberculosis found that the increasing migrant population has had a drastic influence on the spatial distribution of TB in Beijing. Spatial analysis could provide additional information in addition to common incidence plots [34]. Generally, a decrease was observed with movement to the South. For example, the study in Antananarivo City showed a decrease in clustering with movement towards the southern neighborhood [28]. Another Bayesian conditional auto regressive model for mapping tuberculosis prevalence in India figured out that northeastern states having higher risk of tuberculosis than other regions [35].

\section{Importance of active surveillance and targeted screening}

A study indicated that spatial and temporal information may be useful for targeting testing when access is limited [36] as in a cross sectional geographic information system-based screening for TB, HIV, and Syphilis (GIS-THIS) participants reported high-risk characteristics [18]. And the information that prevalence of infection among household contacts of people with tuberculosis is will guides active case finding [37]. Targeted screening program for discovering persons with TB and LTBI exceeded what would be expected from non targeted screening in a county with a TB incidence of 5.7 per 100,000 population [38]. Systematic characterization of the spatio-temporal distribution of TB cases can widely benefit real time surveillance and guide public health investigations of $\mathrm{TB}$ outbreaks as to what level of spatial resolution results in improved detection sensitivity and timeliness [39]. Improved diagnostic and curative efforts need to be combined with additional preventive efforts [30]. Using GIS and spatial scan statistic indicated that spatial scan statistics methodology used to have a potential use in surveillance of tuberculosis for detecting the true clusters of the disease [25].

\section{Importance of resource allocation and deployment}

It has been shown that the information obtained could contribute to more effective budget allocation, drug distribution and recruitment of human skilled resources, as well as guiding the design of vaccination programs [40]. For instance, a spatial analysis in Gambia showed that systematic use of cluster detection techniques for regular TB surveillance could aid effective deployment of resources [22].

\section{Importance of spatial and temporal analysis of TB distribution to help national TB control programs}

The spatial pattern highlight the importance of the data recorded in the TB registry and the use of spatial approaches for assessing the epidemiological situation for TB [41] and local heterogeneity of 
effectiveness as a result of the complex patterns of disease transmission within communities should be expected [26]. Dynamic analysis allowed to trace the temporal path of the aetiological agent, locate the sources of infection, and characterize the dynamics of disease spreading thereby pointing out the information obtained could contribute to more effective budget allocation, drug distribution and recruitment of human skilled resources, as well as guiding the design of vaccination programs [40]. Using GIS and spatial scan statistic it was indicated that spatial scan statistics methodology used to have a potential use in surveillance of tuberculosis for detecting the true clusters of the disease [25]. High-incidence hotspots may play an important role in propagating TB epidemics [19]. For example, a study showed that genotyping combined with geographic information systems analysis can potentially be used to define high-risk status and to define areas for location-based TB screenings [38].

\section{Importance of regional DR-TB monitoring planning and prevention and control strategies}

Spatial variability in latent synthetic risk factors on drug resistance tuberculosis (DR-TB) indicated the need for formulating regional DR-TB monitoring planning and prevention and control strategies, based on the spatial characteristics of the latent synthetic risk factors and spatial variability of the local relationship between DR-TB and latent synthetic risk factors [23]. For example, the spatial pattern of TB in Antananarivo and the contribution of national control program indicators to this pattern highlight the importance of the data recorded in the TB registry and the use of spatial approaches for assessing the epidemiological situation for TB. These findings may also be useful for guiding decisions related to disease control strategies [41].

In summary, new approaches, such as mapping and spatial analysis, may be of value in contributing to basic elements of TB control [22]. And spatial analysis is proved to be more useful for studying spread of tuberculosis analysis and modeling of disease analysis [31]. It was also indicated that the Bayesian CAR method is proved to be a useful tool for disease modeling of tuberculosis [35].

\section{Conclusions}

There is sufficient evidence about the existence of statistically significant high-rate space and time TB clustering in most researched areas. There also was spatial variability across study regions. Significant clustering of TB was seen in "TB Epidemic" and hyperendemic "hotspots" often characterized by crowding, HIV infection, unemployment, and other social determinants. General development measures were also dominant explanatory variables within regions, though correlation with TB incidence trends varied geographically. People movement also found to be another risk factor indicating difference in TB occurrence among countries. Spatial and temporal information may be useful for targeting testing when access is limited.

The information obtained could contribute to more effective budget allocation, drug distribution and recruitment of human skilled resources, as well as guiding the design of vaccination programs. Spatial variability in risk factors on DR-TB indicated the need for formulating and planning regional DR-TB control strategies.

New approaches, such as mapping and spatial analysis, may be of value in contributing to basic elements of TB control. And spatial analysis is proved to be more useful for studying spread of tuberculosis analysis and modeling of disease analysis. Scan statistics methodology used to have a potential use in surveillance of tuberculosis for detecting the true clusters of the disease.

\section{Acknowledgement}

It is equally a joy and an honor to thank all staffs of the School of Public Health (SPH) and the Research and Community Services Core Process (RCSCP), University of Gondar, for their intellectual stimulus, personal encouragement, and institutional support.

\section{References}

1. WHO (2011) Global tuberculosis control Report.

2. www.righthealth.com

3. Tiemersma EW, van der Werf MJ, Borgdorff MW, Williams BG, Nagelkerke NJ (2011) Natural history of tuberculosis: duration and fatality of untreated pulmonary tuberculosis in HIV negative patients: a systematic review. PLoS One 6: e17601.

4. United Nations (2008) The Millenium Development Goals Report.

5. WHO (2010) Global Tuberculosis Control.

6. Borgdorff MW, Floyd K, Broekmans JF (2002) Interventions to reduce tuberculosis mortality and transmission in low- and middle-income countries. Bull World Health Organ 80: 217-227.

7. World Health Organization (2009) Global Tuberculosis Control 2009: Epidemiology, Strategy, Financing. World Health Organization, Geneva, Switzerland.

8. Borgdorfff Martien W (2004) New Measurabie Indicator for Tuberculosis Case Detection. EID Journal 10.

9. WHO (2006) THE STOP TB STRATEGY: Building on and enhancing DOTS to meet the TB-related Millennium Development Goals.

10. WHO Tuberculosis Programme (1994) WHO Tuberculosis Programme: framework for effective tuberculosis control. Geneva, World Health Organization.

11. WHO (2002) An expanded DOTS framework for effective tuberculosis control Geneva, World Health Organization. In. Edited by (WHO/CDS/TB/2002.29).

12. World Medical Association (WMA), Lilly (2008) The World Medical Association and Lilly multidrug-resistant tuberculosis programme: Plan of action 2008-2011.

13. Lönnroth K, Castro KG, Chakaya JM, Chauhan LS, Floyd K, et al. (2010) Tuberculosis control and elimination 2010-50: cure, care, and social development. Lancet 375: 1814-1829.

14. Sia IG, Wieland ML (2011) Current concepts in the management of tuberculosis. Mayo Clin Proc 86: 348-361.

15. WHA Resolution (1993) Tuberculosis control programme. In: Handbook of resolutions and decisions of the World Health Assembly and the Executive Board. World Health Organization, Geneva, pp: 1985-1992.

16. Nunes C (2007) Tuberculosis incidence in Portugal: spatiotemporal clustering Int J Health Geogr 6: 30.

17. Onozuka D, Hagihara A (2007) Geographic prediction of tuberculosis clusters in Fukuoka, Japan, using the space-time scan statistic. BMC Infect Dis 7: 26.

18. Goswami ND, Hecker EJ, Vickery C, Ahearn MA, Cox GM, et al. (2012) Geographic information system-based screening for TB, HIV, and syphilis (GISTHIS): a cross-sectional study. PLoS One 7: e46029.

19. Munch Z, Van Lill SW, Booysen CN, Zietsman HL, Enarson DA, et al. (2003) Tuberculosis transmission patterns in a high-incidence area: a spatial analysis. Int J Tuberc Lung Dis 7: 271-277.

20. Chaisson RE, Martinson NA (2008) Tuberculosis in Africa--combating an HIVdriven crisis. N Engl J Med 358: 1089-1092.

21. Lönnroth K, Jaramillo E, Williams BG, Dye C, Raviglione M (2009) Drivers of tuberculosis epidemics: the role of risk factors and social determinants. Soc Sci Med 68: 2240-2246.

22. Touray K, Adetifa IM, Jallow A, Rigby J, Jeffries D, et al. (2010) Spatial analysis of tuberculosis in an urban west African setting: is there evidence of clustering? Trop Med Int Health 15: 664-672.

23. Liu Y, Jiang S, Liu Y, Wang R, Li X, et al. (2011) Spatial epidemiology and spatial ecology study of worldwide drug-resistant tuberculosis. Int $\mathrm{J}$ Health Geogr 10: 50.

24. Lin H, Shin S, Blaya JA, Zhang Z, Cegielski P, et al. (2011) Assessing 
Citation: Woldeyohannes SM, Abera SY (2015) Worldwide Spatial and Temporal Distribution of Tuberculosis (TB). J AIDS Clin Res 6: 452. doi:10.4172/2155-6113.1000452

spatiotemporal patterns of multidrug-resistant and drug-sensitive tuberculosis in a South American setting. Epidemiol Infect 139: 1784-1793.

25. Tiwari N, Adhikari CM, Tewari A, Kandpal V (2006) Investigation of geo-spatial hotspots for the occurrence of tuberculosis in Almora district, India, using GIS and spatial scan statistic. Int J Health Geogr 5: 33.

26. Mills HL, Cohen T, Colijn C (2011) Modelling the performance of isoniazid preventive therapy for reducing tuberculosis in HIV endemic settings: the effects of network structure. J R Soc Interface 8: 1510-1520.

27. Murray CJ, Ortblad KF, Guinovart C, Lim SS, Wolock TM, et al. (2014) Global, regional, and national incidence and mortality for HIV, tuberculosis, and malaria during 1990-2013: a systematic analysis for the Global Burden of Disease Study 2013. Lancet 384: 1005-1070.

28. Randremanana RV, Sabatier $P$, Rakotomanana F, Randriamanantena A Richard V (2009) Spatial clustering of pulmonary tuberculosis and impact of the care factors in Antananarivo City. Trop Med Int Health 14: 429-437.

29. Roza DLd, Caccia-Bava MdCGGe, Martinez EZ (2012) Spatio-tempora patterns of tuberculosis incidence in RibeirÃ£o Preto, State of SÃ£o Paulo, southeast Brazil, and their relationship with social vulnerability: a Bayesian analysis. Revista da Sociedade Brasileira de Medicina Tropical 45: 607-615.

30. Lönnroth K, Raviglione M (2008) Global epidemiology of tuberculosis: prospects for control. Semin Respir Crit Care Med 29: 481-491.

31. Venkatesan P, Srinivasan R (2010) Modeling the Spatial Variogram of Tuberculosis for Chennai Ward in India. Indian Journal of Science \& Technology 3: 167-169.

32. Dye C, Lönnroth K, Jaramillo E, Williams BG, Raviglione M (2009) Trends in tuberculosis incidence and their determinants in 134 countries. Bull World Health Organ 87: 683-691.
33. Kik SV, Mensen M, Beltman M, Gijsberts M, van Ameijden EJ, et al. (2011) Risk of travelling to the country of origin for tuberculosis among immigrants living in a low-incidence country. Int J Tuberc Lung Dis 15: 38-43.

34. Li T, He XX, Chang ZR, Ren YH, Zhou JY, et al. (2011) Impact of new migrant populations on the spatial distribution of tuberculosis in Beijing. Int $\mathrm{J}$ Tuberc Lung Dis 15: 163-168, i-iii.

35. Venkatesan P, Srinivasan R, Dharuman C (2012) Bayesian Conditional Auto Regressive Model For Mapping Tuberculosis Prevalence In India. IJPSR 3: 1-3.

36. Lin HH, Shin SS, Contreras C, Asencios L, Paciorek CJ, et al. (2012) Use of spatial information to predict multidrug resistance in tuberculosis patients, Peru. Emerg Infect Dis 18: 811-813.

37. Verver S, Warren RM, Munch Z, Richardson M, van der Spuy GD, et al. (2004) Proportion of tuberculosis transmission that takes place in households in a high-incidence area. Lancet 363: 212-214.

38. Moonan PK, Oppong J, Sahbazian B, Singh KP, Sandhu R, et al. (2006) What is the outcome of targeted tuberculosis screening based on universal genotyping and location? Am J Respir Crit Care Med 174: 599-604.

39. Higgs BW, Mohtashemi M, Grinsdale J, Kawamura LM (2007) Early detection of tuberculosis outbreaks among the San Francisco homeless: trade-offs between spatial resolution and temporal scale. PLoS One 2: e1284

40. Zorzenon dos Santos RM, Amador A, de Souza WV, de Albuquerque MF, Ponce Dawson S, et al. (2010) A dynamic analysis of tuberculosis dissemination to improve control and surveillance. PLoS One 5: e14140.

41. Randremanana RV, Richard V, Rakotomanana F, Sabatier P, Bicout DJ (2010) Bayesian mapping of pulmonary tuberculosis in Antananarivo, Madagascar BMC Infect Dis 10: 21 